\title{
MIDAS
}

Museus e estudos interdisciplinares

$11 \mid 2020$

Dossier temático: "Perspetivas sobre o museu eclético"

\section{A Casa-Museu Fernando de Castro: das coleções e das fantasmagorias}

The Fernando Castro House Museum: collections and phantasmagorias

\section{Raquel Henriques da Silva}

\section{OpenEdition}

\section{Journals}

Edição electrónica

URL: http://journals.openedition.org/midas/1978

DOI: $10.4000 /$ midas. 1978

ISSN: 2182-9543

\section{Editora:}

Alice Semedo, Paulo Simões Rodrigues, Pedro Casaleiro, Raquel Henriques da Silva, Ana Carvalho

\section{Refêrencia eletrónica}

Raquel Henriques da Silva, « A Casa-Museu Fernando de Castro: das coleções e das

fantasmagorias », MIDAS [Online], 11 | 2020, posto online no dia 19 novembro 2020, consultado no dia

21 novembro 2020. URL : http://journals.openedition.org/midas/1978 ; DOI : https://doi.org/10.4000/ midas. 1978

Este documento foi criado de forma automática no dia 21 novembro 2020

\section{(i) $\$(2)$

Midas is licensed under a Creative Commons Attribution-NonCommercial-ShareAlike 3.0 International License 


\title{
A Casa-Museu Fernando de Castro: das coleções e das fantasmagorias
}

The Fernando Castro House Museum: collections and phantasmagorias

\author{
Raquel Henriques da Silva
}

\section{NOTA DO EDITOR}

Artigo recebido a 12.02.2019

Aprovado para publicação a 15.03.2020

Um museu é um instrumento óptico (Vale 2014,

$\mathrm{s} / \mathrm{p})$

\section{O homem e o coleccionador}

Fernando de Castro, poeta e artista de singular temperamento, com ter nascido rico, porque era filho de homem rico, teve de cumprir a fatalidade do seu destino. E assim, pela vida fora, num sonho de poeta e de artista, com o dinheiro que lhe sobrava, em vez de tentar operações aventurosas na Bolsa, foi carreando e amontoando materiais para a realização de sua obra máxima, em que inverteu não só o montante das economias, como o melhor de 35 anos de vida. ${ }^{1}$

1 Fernando de Castro (1889-1946) tem uma biografia singular que, até hoje, mantém zonas de obscuridade. Filho de um próspero comerciante portuense (com escritório na Rua das Flores) trabalhou com o seu pai desde o começo da juventude e, depois da morte daquele, em 1918, continuou a assegurar a firma comercial de onde retirava os meios para manter a célula familiar, restrita à mãe e à irmã. ${ }^{2}$

2 Seguindo práticas bastante habituais numa burguesia abastada, Fernando de Castro (FC) tinha a sua verdadeira vida à margem do escasso desempenho profissional: foi poeta $\mathrm{e}$ escritor (embora de uma obra pouco relevante) e, mais empenhadamente, caricaturista com algum talento ${ }^{3}$, dentro de um esquema imagético de matriz naturalista, sem 
desconhecer as simplificações de traço e de cor dos modernistas. Mas a imortalidade conquistou-a FC com a casa onde viveu e morreu, da decoração da qual se ocupou talvez desde a adolescência, mas com maior certeza a partir da morte do pai, ocorrida, como já referi, em 1918, tinha ele quase 30 anos. A partir de então, FC foi construindo uma casa que, portas para dentro, se foi tornando um museu, numa intensa deliberação, assente no seu gosto pessoal.

Poucos anos antes de falecer, com 57 anos, ele começou a abrir o futuro, organizando, pelo menos uma, mas talvez mais recepções para as quais convidou alguns jornalistas. ${ }^{4}$ Este é um facto muito relevante por duas ordens de razões: em primeiro lugar, permite perceber (nomeadamente pelas fotografias publicadas) que a obra (ou seja, a organização dos diversos recheios dentro da casa) estava, no essencial, como hoje podemos vê-la nas salas principais; em segundo lugar, regista parte do discurso de boas-vindas do colecionador. Assim, os artigos de jornais publicados na ocasião são os únicos documentos sobre o seu pensar e o seu sentir, uma vez que, muito provavelmente por decisão da irmã, não há nem arquivo, nem inventário, nem correspondência de FC capaz de esclarecer as suas opções, as suas hesitações e determinações e, portanto, também não a proveniência das peças que ele seleccionou para marcar a imensa particularidade da sua casa-museu..$^{5}$

Recordando que falou para «cerca de sessenta convidados» (Ribeiro 2013, 279), disse ele, segundo artigo publicado no Comércio do Porto de 23 de Maio de 1944, em plena Segunda Guerra Mundial:

[...] Não imaginara eu, ao principiar esta obra, que me caberia a honra da presença de V. Ex.as a verificá-la. Modesto que sou, não resisti a pedir a V. Ex.as a gentileza desta visita, e, isto porque não me sentia bem sem ela. Alguém que realize uma obra, tão pequena que seja, como neste caso, não descansa, enquanto a não comunica. Tôda a obra tem no artista o seu elemento criador e tem no público o seu elemento definitivo, e a obra não surgirá, não resultará senão assim. Qualquer realização sem crítica não terá o Sol que ilumine e eis porque, V. Ex.as neste dia, encheram de luz a minha casa, da luz em que brilham as maiores fulgurações da literatura, da ciência, da oratória e da arte portuguesa. Se a alta sensibilidade de $\mathrm{V}$ Ex.as dentro da sua tolerância e generosidade, encontrarem nesta casa um momento de emoção eu terei bendito a hora em que nela pensei e recolhido para meu prêmio e consôlo a mais enternecedora alegria. Bem hajam assim, V. Ex.as pela honra eminente que me deram vindo aqui, e agradeço bem do coração, essa cativante gentileza. Estou certo de que o gênio dos artistas maravilhosos, de tantas e tantas gerações, nesta casa representados, também neste momento, agradecem, do além, o culto e o amor de V. Ex.as pela sua obra gloriosa.

Neste empenhado discurso, FC assume-se como um verdadeiro coleccionador: a "obra" realizada, ainda que "modesta" só fica completa quando é comunicada, capaz de gerar "um momento de emoção" aos que a ela acedem, porque absorveriam "o génio de artistas maravilhosos, de tantas e tantas gerações, nesta casa representados". Ficamos com pena que o nosso coleccionador não tivesse escrito mais; no panorama português, creio que não houve outros coleccionadores que tenham enunciado com tanta clareza o desejo maior do coleccionador: partilhar a colecção, pelos seus valores próprios, mas também enquanto partilha de si mesmo.

\section{A tipologia da Casa-Museu Fernando de Castro}

[...] Casa com museu, casa e museu, casa no museu...

Casa onde se instala um museu, museu que se instala numa casa... 
Casa que imita um museu, museu que imita uma casa...

Casa que parece um museu, museu que parece uma casa...

Museu com casa, museu e casa, museu na casa...

Museu habitado [...]. (Rocha 2006, 15)

6 A epígrafe que introduz este subcapítulo, citando Marta Rocha (2006), permite, com clareza, definir a tipologia desta casa-museu no contexto amplo e diversificado do domínio. É "museu na casa" e/ou um "Museu habitado". Tem, em Portugal, congéneres ilustres: a Casa-Museu dos Patudos, fundada por José Relvas (1859-1929) nos primeiros anos de 1900, em casa projectada pelo arquitecto Raul Lino que, com ele, minuciosamente organizou a maioria das salas, em função das colecções reunidas, definindo uma imagem final poderosa e qualificadíssima que, no essencial, ainda hoje se mantém; a Casa-Museu Dr. Anastácio Gonçalves (1888-1965), adquirida, organizada e estabilizada, no essencial, pelo seu fundador, na casa que adquirira no início da década de 1930, aureolada pelo prestígio de ter sido, antes, casa-atelier de José Malhoa, um dos pintores que Anastácio Gonçalves mais admirava; finalmente, a Casa-Museu Medeiros e Almeida (1895-1986), organizada a partir da década de 1960, em casa adjacente à morada do coleccionador, por ele decorada e estruturada nas várias secções da sua portentosa colecção.

7 FC foi um modesto coleccionador quando comparado com os gigantes que acabei de referir, mas tem, em comum com eles, o essencial: o Museu é instalado em casa própria, elaborado ao longo de um tempo relativamente longo e tendo como alvo a sua institucionalização. José Relvas, Anastácio Gonçalves, Fernando de Castro e Medeiros e Almeida foram homens mais ou menos ricos, mais ou menos poderosos, que unimos pela paixão dos objectos que determinaram o seu espaço de vida e das suas famílias. Viveram em casas que já eram museus, feitos por eles e que, muito cedo, decidiram que iriam doar à comunidade, certos de assim assegurar a permanência dos acervos cujo crescimento, por decisão estipulada, não continuou para lá das suas mortes. Hoje são, com os seus nomes próprios, a sua deliberada imortalização.

8 Não cabe, na economia deste artigo, analisar as diferenças consideráveis entre estas quatro casas-museus. Considera-se apenas o mais óbvio: FC foi o menos rico dos quatro coleccionadores, o menos reconhecido socialmente, mas tem uma particularidade a assinalar. Foi o único artista, embora esse estatuto não fosse o que o caracterizou socialmente nem, evidentemente, a origem da sua capacidade financeira. A sua produção de caricaturista é curiosa, registando algumas das personalidades da intelectualidade portuense do seu tempo, mas também, como marca própria, uma ampla representação de cidades, vilas e lugares de Portugal, partindo dos seus nomes para montar pequenas cenas humorísticas que provocam imediatamente o riso. É uma obra quase desconhecida que, na minha opinião, merecerá um estudo monográfico contextualizado no desenho humorístico português. ${ }^{6}$

9 Mas volto de novo à comparabilidade entre os quatro coleccionadores citados. Além de ser o menos rico e o menos relevante em termos do reconhecimento social do seu tempo, FC distingue-se também pelo enfoque particularíssimo das suas opções de coleccionador, a partir do facto comum de todos eles admirarem mais a arte do passado do que a do seu próprio tempo, ou elegerem, no seu tempo, as continuidades em relação às estilísticas do passado e não as rupturas que vão compondo o corpo múltiplo da modernidade. Sobre estas similitudes, interessa finalmente tratar a poderosa a marca autoral de FC. 


\section{O gosto do coleccionador}

Devassar, percorrer, esmiuçar, com a vista, o recheio dessa residência de artista, é como folhear um volumoso álbum de mágicas estampas a cores, que se combinam por grupos como estrofes e, entrando pelos olhos, alcançam a alma, afagando-a, embalando-a, deliciando-a, com sua música de timbres aveludados, abafados, espiritualizados. [...]

Algumas das divisões da casa-museu dão ao visitante a impressão de abarrotadas de peças até à congestão, mas ao observador atento e minucioso não escapará o critério de ordem que ditou o arrumo de tudo quando, ali dentro, se expõe. ${ }^{7}$

10 A casa de FC não é grande, embora ocupe, na Rua Costa Cabral, três lotes sucessivos, comprados em momentos diversos e unidos, nas traseiras, pelo jardim. No entanto, a parte da casa que nos interessa é aquela em que ele viveu e musealizou (Rocha 2006).

11 Não cabe, nos objectivos deste texto, a descrição minuciosa de cada uma das principais salas e, ainda menos, dos seus recheios. No entanto, só este trabalho - que continua por fazer - permitirá compreender melhor o gosto do coleccionador e a sua eventual progressão ao longo de 30 anos. Acrescente-se que as designações que vamos usar para apresentar as sucessivas salas têm origem nos artigos de jornal escritos em vida de FC.

Creio que a Sala minhota (fig. 1) a primeira em que se entra, se não avançarmos pelo corredor, terá sido a primeira a ser organizada. Há nela já os quatro principais elementos caracterizadores de toda a casa: o uso extensivo da talha dourada que cria paredes e tectos artificiais sobre os quais a imensa diversidade de objectos e também de alguns móveis se suspendem ou encaixam; a sobreposição de tipologias numa densidade tal que impede de atentarmos em cada uma das peças de per si, sejam elas mobiliário, escultura, cerâmica, faiança ou pintura; a mistura intencional entre artes religiosas e não religiosas; a estranheza provocada por alguns objectos e móveis porque rapidamente se percebe que resultam de fusões, colagens ou recriações de outros de origens diversas. 


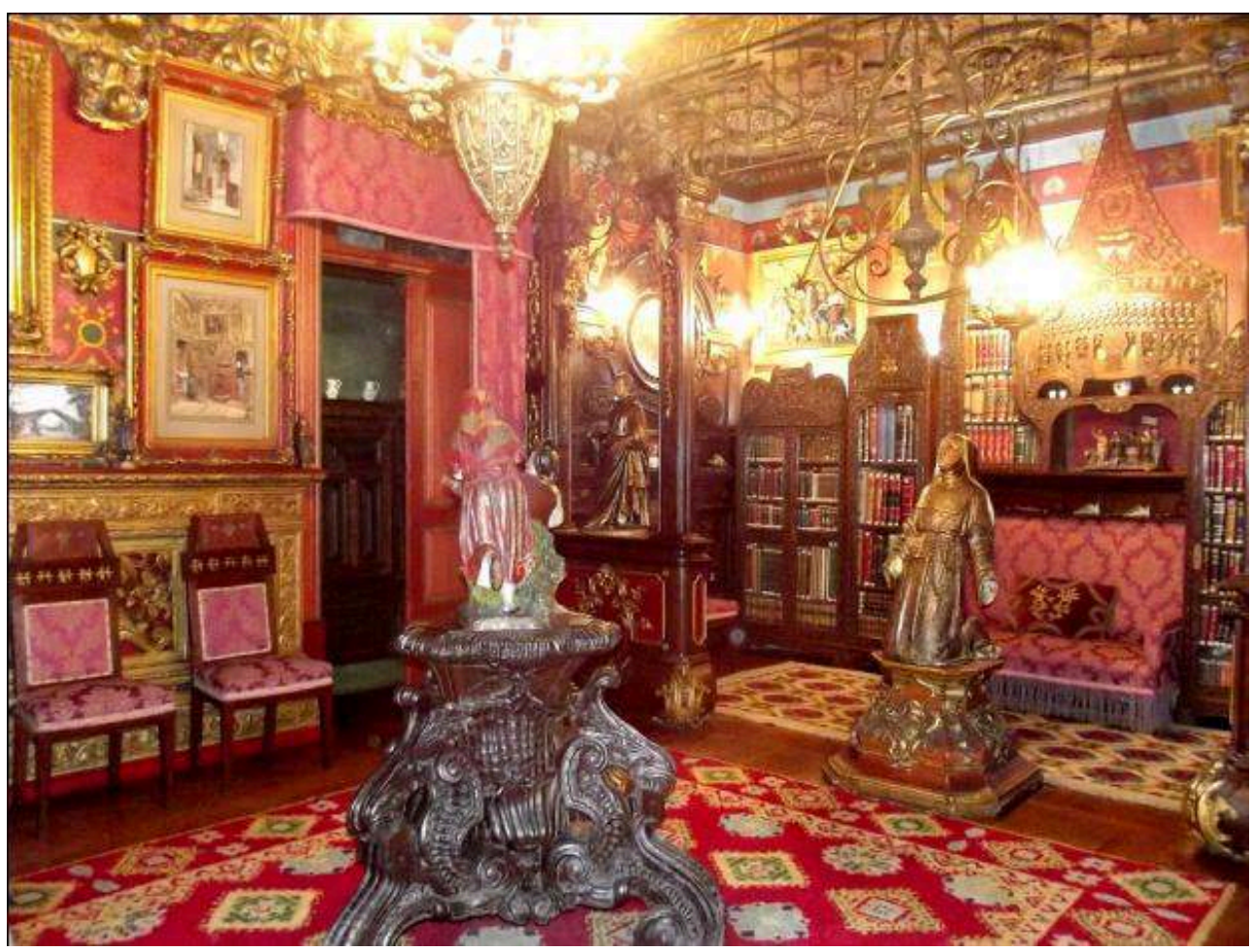

Fig. 1 - Casa-Museu Fernando de Castro, Sala minhota

Arquivo Fotográfico do Museu Nacional de Soares dos Reis. Fotografia de Filipa Gonçalves

13 Mas, sobre estas evidentes opções, há um gosto casticista pelas artes populares que não voltaremos a encontrar nas salas seguintes. São apontamentos materiais de formas, de objectos ou parte deles que foram escolhidos para representar o que então se entendia pelas artesanais minhotas, na sua feição relativamente modesta. Em lugar de destaque da sala, somos vistos pela fotografia dos pais de Fernando de Castro, como se os filhos quisessem que eles velassem sobre a casa directamente deles herdada.

14 Na vizinha casa de jantar, a densidade da talha dourada acentua-se, gerando uma ambiência onírica que duplamente nos deslocaliza. Temos à nossa escala, a envolvernos, a talha dourada que nos habituámos a ver à distância, nos retábulos de tantas igrejas; no entanto, o que nos é proposto não é o espaço sagrado, mas a sua laica apropriação cenográfica: um palco para os outros objectos e para nós próprios que ocupamos o lugar do coleccionador. Mas mantém-se o jogo duplo e sinuoso: ele olharia à volta com o nosso espanto maravilhado, mas também com a memória arguta da construção de cada peça e de cada conjunto que são patch works avassaladores.

15 O pequeno corredor, por onde se avança, acentua, agora numa dimensão de percurso, as contraditórias sensações que ali confluem: tudo é apertado mas nada nos aperta, como acontece com a "abertura" que conduz Alice ao "outro lado do espelho", onde se destroem todas as convenções sobre pequeno e grande, sobre paisagem exterior e paisagens interiores. Há peças interessantes, cerâmicas, pinturas, madeiras, faianças, sabiamente dispostas como se tivessem nascido ali, debruçadas sobre espelhos oportunos que as repetem na sua verdadeira existência: são imagens cuja realidade matérica, histórica e artística, se dissipa em orquestração inusitada.

Mais do que os corredores, os dois conjuntos de escadas que ligam o $\mathrm{r} / \mathrm{c}$ e o $1 .^{\circ}$ andar (fig. 2) e este com o 2. (fig. 3) constituem a apoteose da estética de FC. Continuamos a mover-nos numa cenografia deliberada que usa o culto do sagrado contra-reformista 
para acumular texturas que advêm das matérias, das atitudes, da sobreposição, das convexidades.

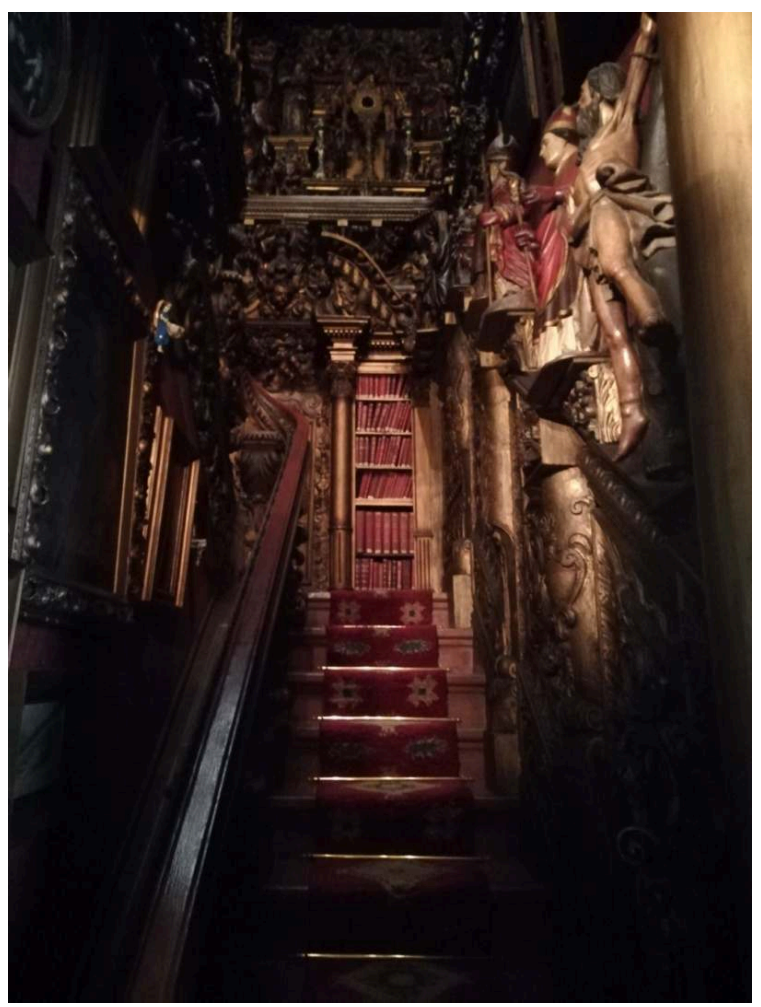

Fig. 2 - Casa-Museu Fernando de Castro, escada de acesso ao $1 .^{\circ}$ andar Fotografia da autora

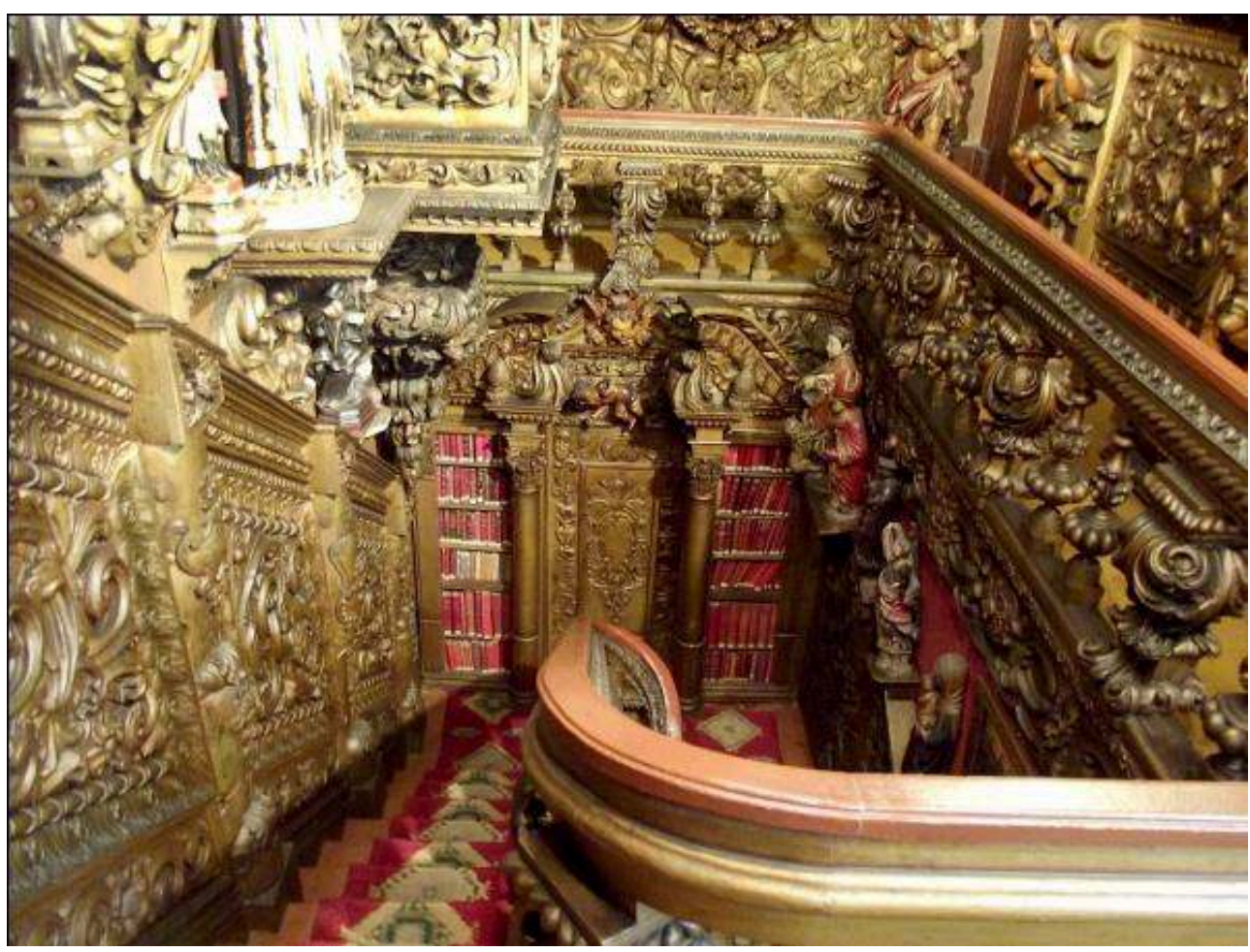

Fig. 3 - Casa-Museu Fernando de Castro, escada de acesso ao 2. ${ }^{\circ}$ andar

Arquivo Fotográfico do Museu Nacional de Soares dos Reis. Fotografia de Filipa Gonçalves 

pictóricos requerem uma análise cuidada, bem como a expressividade da escultura, ora disposta em friso, ora cavalgando o corpo restrito da escada. A nós parecem-nos uma poderosa unidade, mas trata-se de colagens e adições que advêm, segundo o testemunho dos jornalistas que visitaram a casa em 1944, de conventos extintos da região de Braga.

Para os especialistas destas áreas da história da arte, aqueles falsos conjuntos devem ser decompostos e contextualizados, mas FC montou a cena para nós, visitantes que não paramos de ver, imersos num universo que tem na realidade a sua absoluta fantasmagoria. Para conseguir o seu objectivo, cortou, colou, misturou, mas sem ignorar os valores expressivos em presença, antes potenciando-os nos espaços verticalizantes das estreitas escadas da sua casa.

19 Apesar de estas operações de reconfiguração da arte religiosa ocorrerem um século depois da extinção dos conventos, sobrevivia ainda (sobreviverá hoje?) um estranho gosto por parte de amantes do passado como FC: quase todos consideravam que aquela decisão política fora acertada porque as funções seculares que os conventos haviam desempenhado pertenciam agora ao Estado - e porque eles haviam crescido não tanto por exigência de vocação, mas para resolver diversos problemas sociais - mas esses lugares-outros que eles constituíam ("heterotopias" no sentido de Michel Foucault ${ }^{8}$ ) eram poderosas máquinas de atracção. Houve quem, no início da profunda transformação, comprasse os edifícios conventuais para aí viver (como D. Fernando de Saxe Coburgo em relação ao Convento de Nossa Senhora da Pena, em Sintra) e outros que, como FC, os transportaram para dentro das suas próprias casas, dotando-as de portentosa retórica de denegação das atribuições da arquitectura.

Nas salas do primeiro andar, o furor decorativo de pulsão barroca acalma-se. Assim, na bela Sala dourada ou Sala de baile (fig. 4), há uma leveza predominantemente rocaille, embora constituída com as mesmas ferramentas de corte e cola. Mas a luz natural que entra pelas janelas, os espelhos que, com amplitude, multiplicam a cena, o equilíbrio cromático que se estende aos cortinados, sugere uma atitude diversa por parte do coleccionador: é um espaço de visita e de representação que acolhe com tranquilidade quem vem de fora, libertando-os do excesso de impressões que haviam acumulado ao subir as escadas. 


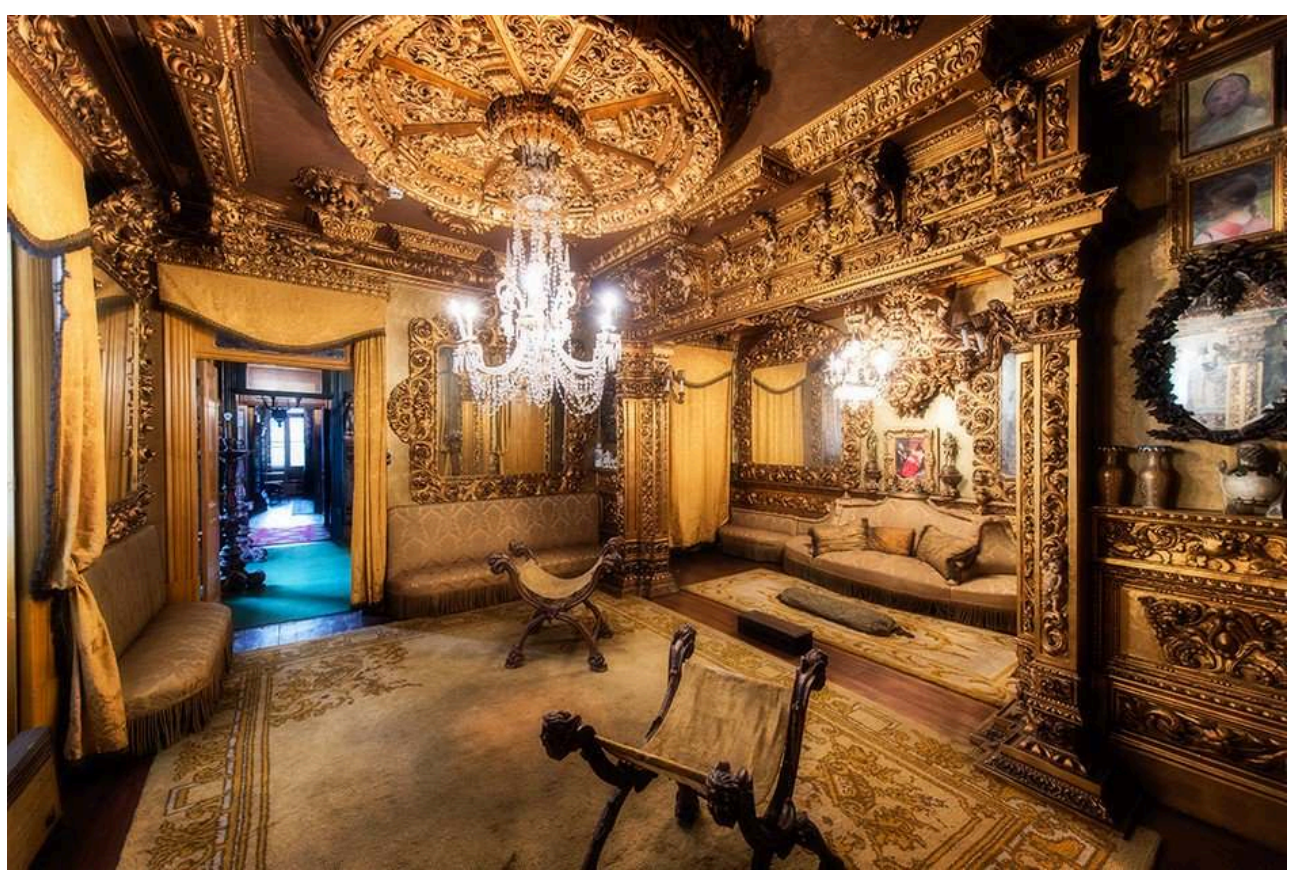

Fig. 4 - Casa-Museu Fernando de Castro, Sala dourada

Arquivo Fotográfico do Museu Nacional de Soares dos Reis. Fotografia de Filipa Gonçalves

21 Algo de semelhante acontece com a Sala azul, onde a talha se restringe a pontos tónicos de articulação do tecto com as paredes, deixando espaço de representação à interessante colecção de pintura portuguesa, sobretudo do longo ciclo do naturalismo, revelado na década de 1880 e que se mantinha como referência de gosto ainda nos anos de 1930 e 40. Há a considerar também os móveis e, sobretudo, a biblioteca operosa, manifestando o mesmo gosto tradicional e conservador, reiterando os valores de modernidade anteriores à Primeira Guerra Mundial.

Depois de se voltar ao último lance de escadas, mergulhando mais uma vez em imersão sensorial, no último piso, é a visita ao quarto que nos atrai (fig. 5). 


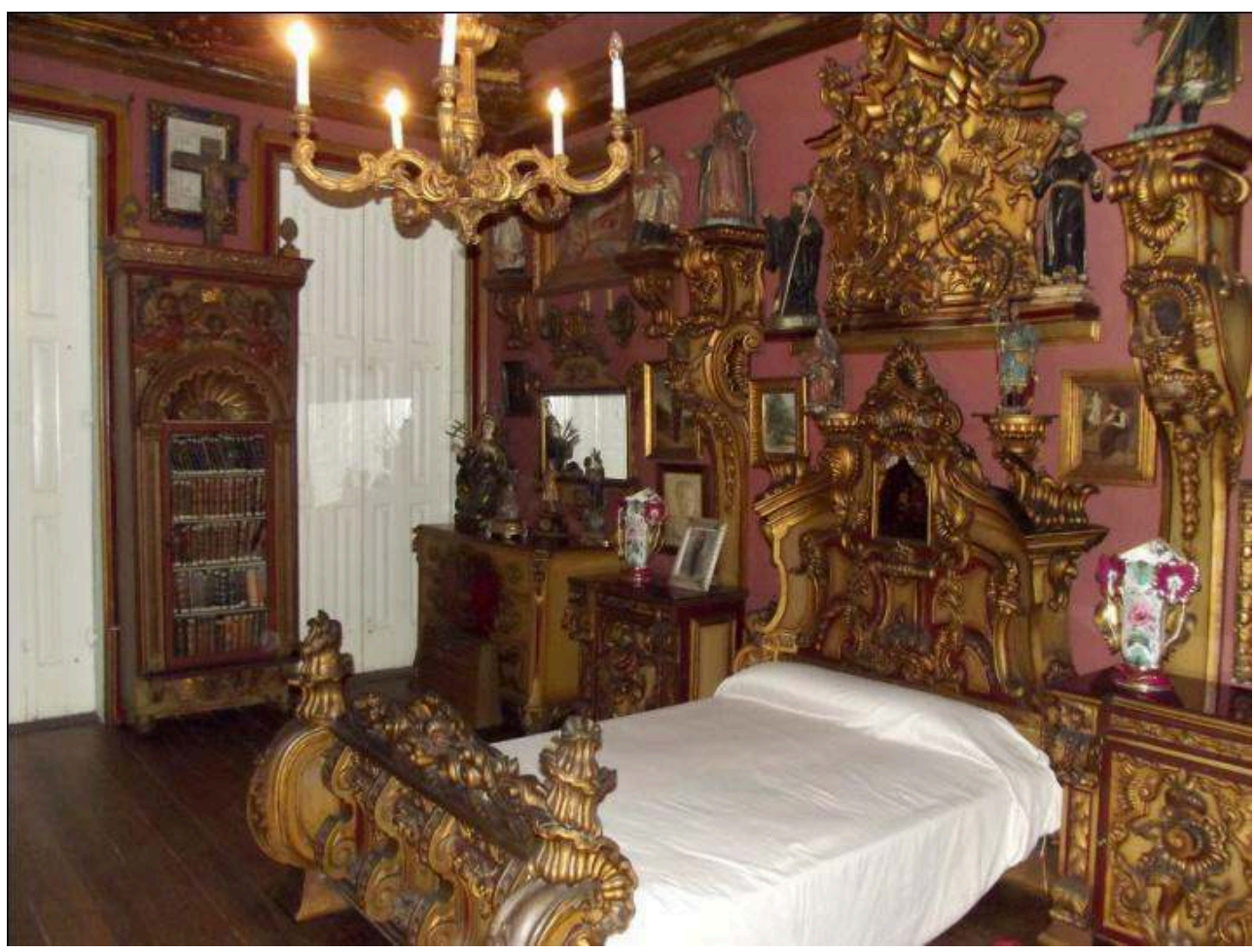

Fig. 5 - Casa-Museu Fernando de Castro, quarto de dormir

Arquivo Fotográfico do Museu Nacional de Soares dos Reis. Fotografia de Filipa Gonçalves aberto e controlado, sugerindo um cosmopolitismo algo dandy: deixando para trás o homem que desmantelou, recolheu e reinstalou retábulos, tectos, oratórios, coros e sanefas, talvez para deixar respirar o caricaturista que, pelo menos na juventude, frequentou os lugares de moda da abastada burguesia portuense.

\section{Reflexão provisória}

Desde que, por doação de Maria da Luz Castro, irmã de FC, a Casa entrou no património do Estado, através da tutela do Museu Nacional de Soares dos Reis, ela tem sido motivo de encantamento para gerações sucessivas de conservadores. Desde logo, por Vasco Valente, director do Museu desde 1934, que, em 1950, iniciou o primeiro inventário do seu recheio, infelizmente interrompido pela sua morte, apenas dois meses mais tarde. Sucedeu-lhe, no cuidado da Casa, Maria Clementina Quaresma e, mais recentemente, Catarina Maia e Castro e Vera Calem.

Atravessaram-se momentos difíceis, nunca se concretizaram projectos mais ambiciosos para a valorização desta unidade museológica, mas ela manteve-se, transportando até nós, quase 100 anos depois, a energia fantasmática com que foi dotada por FC. Por isso, torna-se inesquecível para todos os visitantes e ninguém duvida que os actuais e futuros responsáveis, continuarão a manter este notável "museu de museu”, designação com que Joana Baião definiu os museus que, pela permanência da sua museografia inicial, se tornaram, eles próprios, objectos museológicos ampliados (Baião 2009).

Termino com algumas reflexões ainda sem resposta. Será que FC foi um coleccionador? A pergunta pode parecer descabida, tendo em conta o espólio de largas centenas de 
objectos que existem na Casa. No entanto, a importância do seu legado não advém dos melhores conjuntos onde se pode intuir um impulso colecionista, como sejam a pintura ("Antiga" e, sobretudo, dos séculos XIX-XX) e escultura sacra. Deste ponto de vista, a hierarquia do valor, histórico e estético, está definida, graças ao trabalho dos conservadores já referidos e, no actual momento, de José Costa Reis. Mas, em relação à talha e à maioria da escultura devocional, o que há é uma disposição/adequação aos espaços da Casa que ganha o protagonismo maior. Admito que FC tenha comprado por gosto de cada peça, nomeadamente no que se relaciona com a pintura mais ou menos sua contemporânea. Mas, quando entram na Casa, esses objectos, com autoria própria, parece que se fundem naquele espaço irradiante, dialogando com os que lá estavam, sobre fundos artificiais e confrontos inusitados. Ou seja, as diversas colecções, caso existam com alguma coerência, subsumem-se na entidade Casa, peças relacionadas de um discurso próprio que é, para voltarmos a citar Marta Rocha, um "museu habitado".

A segunda questão é mais ampla e inconclusiva. Na estética de sobreposição e de horror ao vazio, que caracteriza a museografia de $\mathrm{FC}$, existirá uma pulsão kitch, termo que aqui uso no sentido de mistura criativa entre alta e baixa cultura, sobre considerável indiferença aos saberes compendiados da História da Arte?

Julgo que sim, mas qualquer resposta mais cuidada exige a documentação das peças de origem, sobretudo no que se refere às que foram transladadas, adaptadas e recriadas. Desaparecida toda a documentação pessoal, dificilmente se apurará com que mestres, marceneiros e carpinteiros, trabalhou FC. Será difícil também avaliar a dimensão das suas apropriações e reconfigurações. Mas, sobre aquele imenso labor de encaixes sucessivos, cobrindo paredes e tectos, e muito especialmente os dois conjuntos de escadas, há uma dimensão faber a ter em conta que, com imensa particularidade, não deixa de sugerir as práticas de bric-à-brac que são comuns nas culturas de decoração doméstica do século XIX. Resta finalmente pensar, neste domínio, se o kitch não possui também uma dimensão ingenuísta que, de modo diverso, existe também na produção de desenho satírico de FC, no que toca ao jogo com os nomes de vilas, cidades e aldeias.

Termino com uma terceira questão para a qual definitivamente não tenho resposta: qual a razão de ser de um amor tão convulsivo pela talha dourada ou que ele dourou e nem sempre com os melhores materiais? À época, a talha era uma estética mal-amada. É bem possível que conjuntos adquiridos por FC tenham vindo das intervenções patrimoniais da Direcção Geral dos Edifícios e Monumentos Nacionais que, em nome da "unidade de estilo" à Viollet-le-Duc, despojou muitos monumentos portugueses dos seus recheios de talha. Porquê então essa opção contra a corrente?

Creio que a resposta estará mais na psicologia do que na história. Aquele homem, que parece ter sido sempre discreto e reservado, viveria dominado pelo desejo da representação e do teatro para que a vida, portas adentro de uma casa de fachada anónima, pudesse ter a intensidade da festa que é tão falsa como verdadeira. Exactamente como os fantasmas. 


\section{BIBLIOGRAFIA}

Afonso, Micheli Martins. 2013. “A Reconstrução da Memória de uma Casa-Museu: Diagnóstico de Conservação de uma Amostragem da Colecção de Pintura da Casa Museu Fernando de Castro Porto. Portugal." Bacharelato em Conservação e Restauro, Universidade Federal de Pelotas.

Baeta, Ricardo Manuel. 2010. "Coleccionismo Privado no Porto. Colecções e Colecionadores de Arte na Revista Ilustração Moderna (1926-1932).” Dissertação de mestrado em Museologia, Universidade de Lisboa.

Baião, Joana. 2009. “"Museus de Museus', uma Reflexão. Proposta para uma Definição.” Dissertação de mestrado em Museologia, Universidade Nova de Lisboa.

Foucault, Michel. 1997. "Of other Spaces: Utopias and Hererotopias." In Rethinking Architecture: A Reader in Cultural Theory, ed. Neil Leach, 350-355. New York: Routledge.

Ponte, António Manuel Torres. 2007. “Casas-Museu em Portugal: Teorias e Práticas.” Dissertação de mestrado em Museologia, Universidade do Porto.

Ribeiro, Vera de Almeida. 2013. "Fernando de Castro e a sua Casa." Mvseu, IV série, n.ำ 20: 259-292. Rocha, Hugo. 1952. “A Casa-Museu de Fernando de Castro.” O Tripeiro do Porto, V série, ano VII, n.o 12 , p. 268.

Rocha, Marta, 2006. “Da Casa ao Museu. Adaptações Arquitectónicas nas Casas-museu em Portugal.” Dissertação de mestrado em Metodologias de Intervenção no Património Arquitectónico, Universidade do Porto.

Santos, Paula Leite. (no prelo). “Fernando de Castro.” In Dicionário Quem é Quem na Museologia Portuguesa, coord. Emília Ferreira, Joana d'Oliva Monteiro e Raquel Henriques da Silva. Lisboa: Instituto de História da Arte da Faculdade de Ciências Sociais e Humanas da Universidade Nova de Lisboa.

Vale, Paulo Pires do. 2014. "Jerónimo e a Esfinge. Os olhos Pensam, a Mão vê, a Palavra Toca." In Tratado dos Olhos. Catálogo de exposição, s/p. Lisboa: Atelier-Museu Júlio Pomar.

\section{NOTAS}

1. In Jornal de Notícias, 23 de Maio de 1944, transcrito por Micheli Afonso $(2013,24)$.

2. A autora escreve de acordo com a antiga ortografia.

3. A melhor biografia de Fernando de Castro foi elaborada por Vera de Almeida Ribeiro (2013). Ver nomeadamente p. 267 e seg. Pode ser completada com Micheli Afonso (2013, p. 28 e seg.).

4. Ver 0 Comércio do Porto, 21 de Maio de 1944 e $O$ Primeiro de Janeiro, 23 de Maio de 1944. Logo à entrada da Casa, existem duas placas que registam a visita de dois bispos: D. António Meirelles, em 1938, e D. Manuel Gonçalves Cerejeira, em 1949, depois do falecimento de FC e que só pode ter sido promovida e comemorada por sua irmã, D. Maria de Castro. Ver Vera de Almeida Ribeiro $(2013,281)$.

5. Remeto o desenvolvimento deste tópico para o artigo de Vera de Almeida Ribeiro que tenho vindo a citar. Mas não posso deixar de alertar que o tema merece desenvolvimento de investigação, não só para documentar o acervo da Casa mas também a biografia do seu fundador. 6. Segundo Micheli Afonso $(2013,19)$, a «coleção de pintura possui aproximadamente 700 obras. Destas, cerca de 300 peças correspondem às caricaturas executadas pelo patrono da Casa-Museu, 
Fernando de Castro». Mais adiante, na p. 30, a mesma autora recorda que «As caricaturas estão atualmente expostas na Casa-Museu consonante a determinação de Maria da Luz de Araújo e Castro» e de acordo com o Documento de Doação da CMFC ao Estado, em 1952. Segundo o Comércio do Porto, nas notícias referentes à visita à Casa de Fernando de Castro, «um grupo de intelectuais que ontem visitaram a casa-museu» iria organizar uma exposição das suas caricaturas (Afonso 2013, 34). No entanto, parece que a iniciativa não se concretizou. Antes disso, em 1935, FC designa-se por «Discípulo de Alberto Silva. Amador e colecionador de Arte. Concorreu a várias exposições de Humoristas» (Ribeiro 2013, 276).

7. Hugo Rocha, in O Tripeiro do Porto, 1952, citado por Micheli Afonso (2013, 38-39; 40).

8. Ver Michel Foucault (1997).

\section{RESUMOS}

A Casa-Museu Fernando de Castro (Porto) configura um dos mais fascinantes e secretos museus portugueses. Tutelada pelo Museu Nacional de Soares dos Reis desde a sua instituição, o lugar e as colecções estão salvaguardadas, embora, constrangimentos vários (dos financeiros aos funcionais) impeçam que ela se encontre permanentemente aberta à visita pública, o que, neste caso, reforça a dimensão aurática da sua particularidade. Por outro lado, o facto de não existirem documentos que permitam perceber a proveniência dos objectos e os modos como foram reinstalados deslocam o secretismo do museu para o seu instituidor. Fernando de Castro (1889-1946) coleccionou sobretudo talha dourada oriunda de igrejas e capelas conventuais. Nesse tempo, meados dos anos de 1950, a talha não estava na moda, o que lhe permitiu aquisições a preços relativamente modestos. Mas o cerne da Casa-Museu foi o modo como foram instaladas nos espaços da Casa, segundo uma estética de sobreposição e de excesso. São estes os tópicos de reflexão que constituem este artigo, baseado em bibliografias sucessivamente publicadas.

The House Museum Fernando de Castro (Porto) is one of the most fascinating and secret Portuguese museums. It has been supervised by the Museu Nacional de Soares dos Reis, since its foundation, so the place and its collections are protected, in spite of various constraints (both financial and functional) keep preventing it from being permanently open to public visit. On the one hand, this situation reinforces its particular aura. On the other hand, the fact that there are no documents on the origin of the collection's objects and no clues to the different solutions of their reinstallation, shift the secrecy from the museum to its founder. Fernando de Castro (1889-1946) collected mostly gilded carving from convent churches and chapels. By mid-1950s, gilded carving was not at all fashionable, which made way for acquisitions at a relatively modest price. However, the most important aspect of the House Museum is the way all these objects were installed in the various spaces of the House, according to an aesthetic of excess. These are the topics of reflection that constitute this paper, which is based on the analysis of bibliographies successively published. 
ÍNDICE

Keywords: House Museum Fernando de Castro, private collecting, psychology of collecting, aesthetics of excess, house museums

Palavras-chave: Casa-museu Fernando de Castro, colecionismo privado, psicologia do coleccionismo, estética do excesso, casas-museu

\section{AUTOR}

\section{RAQUEL HENRIQUES DA SILVA}

Professora na Faculdade de Ciências Sociais e Humanas da Universidade Nova de Lisboa, Departamento de História da Arte de que é coordenadora executiva desde 2015. Lecciona seminários do mestrado em História da Arte do século XIX e do mestrado em Museologia; é coordenadora do curso de doutoramento em História da Arte. Autora de estudos de investigação e divulgação nas áreas do urbanismo e arquitectura (século XIX-XX), artes plásticas e museologia. Comissária de exposições de arte. Foi directora do Museu do Chiado (1994-1997) e do Instituto Português de Museus (1997-2002). Integrou o Conselho de Administração da Fundação de Serralves (2000-2006) e, actualmente, integra o Conselho de Administração da Fundação ArpadSzenes-Vieira da Silva. É directora científica do Museu do Neo-Realismo desde 2018.

Instituto de História da Arte, Faculdade de Ciências Sociais e Humanas, Universidade de Lisboa, Colégio Almada Negreiros, Campus de Campolide, 1070-312 Lisboa, Portugal, raquelhs10@gmail.com 